\title{
ANALISIS PERKEMBANGAN KOGNITIF ANAK MELALUI KEGIATAN MENGKASIFIKASIKAN BENDA DI TK SE KOTA SUKABUMI TAHUN PELAJARAN 2017/2018
}

\author{
${ }^{1}$ Alfian Ashshidiqi Poppyariyana, ${ }^{2}$ Aditia Eska Wardana \\ ${ }^{1}$ Universitas Muhammadiyah Sukabumi, ${ }^{2}$ Universitas Muhammadiyah Sukabumi \\ aㅣfiantetepblie@gmail.com, ${ }^{2}$ aditiawardana90@gmail.com
}

\begin{abstract}
Abstrak
Penelitian ini bertujuan untuk menganalisis tingkat perkembangan kognitif pada anak usia 5-6 tahun dengan indikator kemampuan mengklasifikasikan benda sesuai warna, mengklasifikasikan benda sesuai bentuk, dan mengklasifikasikan benda sesuai ukuran. Penelitian ini merupakan jenis penelitian deskriptif dengan pendekatan kuantitatif. Subjek penelitian ini adalah 42 anak di kota dan kabupaten Sukabumi. Metode pengumpulan data yang digunakan adalah observasi, wawancara, dan studi dokumentasi. Analisis data menggunakan teknik analisis deskriptif kuantitatif. Hasil penelitian menunjukkan bahwa kemampuan mengklasifikasikan benda pada anak usia 5-6 tahun di kota dan kabupaten Sukabumi 44,44 \% dengan predikat sangat baik, 31,75\% dengan predikat baik, 16,67 \% dengan predikat cukup baik, dan 7,14 \% dengan predikat kurang baik. Penelitian ini menunjukkan bahwa tingkat perkembangan anak di Sukabumi sudah berkembang dengan sangat baik.
\end{abstract}

Kata kunci: perkembangan kognitif, mengkasifikasikan benda

\begin{abstract}
This research aims to analyze the cognitive level development at the age of 5-6 years with an indicator of the ability to classify objects according to color, classify objects according to shape, and classify objects according to size. This research is a type of descriptive research with quantitative approach. The subjects of this study were 42 children in Sukabumi. Data collection methods used include observations, interviews, and documentation studies. Data analysis is used by quantitative descriptive analysis techniques. The results showed that the ability to classify objects at the age of 5-6 years in Sukabumi is $44.44 \%$ with a very good predicate, $31.75 \%$ with a good predicate, $16.67 \%$ with a pretty good predicate, and $7.14 \%$ with a bad title. This research shows that the development level of children in Sukabumi has developed very good.
\end{abstract}

Keywords: cognitive development, classifying objects 


\section{PENDAHULUAN}

Undang-undang Nomer 20 Tahun 2003 tentang Sistem Pendidikan Nasional Bab I Pasal I butir 14 menyatakan bahwa Pendidikan anak usia dini merupakan suatu upaya pembinaan yang ditujukan kepada anak sejak lahir sampai dengan usia enam tahun yang dilakukan melalui pemberian rangsangan pendidikan untuk membantu pertumbuhan dan perkembangan jasmani dan rohani agar anak memiliki kesiapan dalam memasuki pendidikan lebih lanjut. Anak usia dini berada dalam masa keemasan (golden age). Masa ini merupakan masa untuk meletakkan dasar-dasar pertama dalam mengembangkan kemampuan fisik, kognitif, sosial emosi, bahasa, motorik, nilai moral agama, konsep diri, disiplin, kemandirian, dan kerjasama.

Anak sebagai generasi penerus bangsa yang nantinya akan membangun bangsa indonesia menjadi bangsa yang maju. Masa depan bangsa ditentukan oleh pendidikan yang diberikan anak sejak usia dini. Pendidikan anak usia dini bertujuan untuk mengembangkan seluruh potensi yang dimiliki anak agar kelak dapat berkembang secara optimal. Pengembangan kemampuan tersebut membutuhkan kondisi serta stimulasi yang sesuai dengan kebutuhan anak agar pertumbuhan dan perkembangan anak dapat tercapai secara optimal. Perkembangan secara optimal bisa terwujut apabila dilakukan upaya pembinaan yang terencana, holistik, dan intensif didasarkan pada karakteristik perkembangan anak. Anak usia dini memiliki tingkat pencapaian perkembangan yang berbeda disetiap usia, sehingga diberi perlakuan dan stimulus yang berbeda pula supaya perkembangan anak dapat optimal.

Pada dasarnya pengembangan kognitif dimaksudkan agar anak mampu melakukan eksplorasi terhadap dunia sekitar melalui panca indranya, sehingga melalui pengetahuan yang didapat anak akan dapat melangsungkan hidupnya dan menjadi manusia yang utuh sesuai dengan kodratnya. Kognitif adalah suatu proses berpikir, yaitu kemampuan individu utuk menghubungkan, menilai dan mempertimbangkan suatu kejadian atau peristiwa. Namun kenyataan dilapangan menyatakan bahwa kemampuan kognitif anak masih jauh dari yang diharapkan.

Penelitian ini dilatarbelakangi oleh beberapa fakor diantaranya adalah kenyataan dilapangan bahwa perkembangan kognitif anak masih rendah. Faktor berikutnya adalah guru mengalami kesulitan dalam memberikan stimulus untuk meningkatkan perkembangan kognitif anak, hal ini disebabkan oleh minimnya media pembelajaran dan juga kreatifitas guru dalam memberikan stimulus.

Perkembangan (development) merupakan proses bertambahnya kemampuan dalam struktur dan fungsi tubuh yang bersifat lebih kompleks dengan pola yang teratur dan dapat diramalkan, hal ini merupakan hasil dari proses pematangan. Peristiwa perkembangan ini biasanya berkaitan dengan masalah psikologis seperti kemampuan gerak kasar dan halus, intelektual, sosial dan emosional. Perkembangan seorang anak juga dipengaruhi oleh berbagai faktor seperti: faktor dalam diri (internal) dan faktor lingkungan (eksternal).

Sedangkan kognitif adalah suatu proses berpikir, yaitu kemampuan individu utuk menghubungkan, menilai dan mempertimbangkan suatu kejadian atau peristiwa (Sujiyono, 2004: 1.3). Banyak yang mendefinisikan mencoba sebenarnya apakah kognitif itu, bagaimanapun itu semua bukan hal yang mudah. Seperti kamu hendak melihat, kognitif memili 
arti yang tidak sama dengan yang kita pikirkan dengan apa yang dipikirkan orang lain pada satu waktu.

Anak usia dini sedang berada dalam usia emas (golden age) yaitu sebuah masa yang paling tepat untuk meletakkan dasar-dasar pertama dalam mengembangkan kemampuan fisik motorik, kognitif, bahasa, sosial emosi, nilai moral agama, dan seni. Pengembangan kemampuan tersebut membutuhkan kondisi serta stimulasi yang sesuai dengan kebutuhan anak agar pertumbuhan dan perkembangan anak dapat tercapai secara optimal. Kegagalan untuk berinvestasi pada pendidikan awal ini dapat mengakibatkan keterlambatan pertumbuhan serta menghambat perkembangannya.

Aspek perkembangan kognitif sangat diperlukan oleh anak dalam mengembangkan pengetahuannya tentang apa yang dilihat, dirasa, didengar, diraba, dan juga dicium melalui panca indra yang dimilikinya. Kogntif merupakan suatu proses berfikir, yaitu sebuah kemampuan individu untuk menghubungkan, menilai serta mempertimbangkan suatu peristiwa atau kejadian. Pengembangan kemampuan kognitif dirasa sangat berpengaruh bagi kehidupan anak selanjutnya, karena melalui proses berfikir anak akan lebih terarah hidupnya.

Johnston \& Halocha (2010: 65) berpendapat bahwa perkembangan kognitif melibatkan pengembangan pengetahuan dan pemahaman konseptual, kognisi. Kognisi melibatkan sejumlah keterampilan dan atribut, seperti memori, kemampuan untuk melakukan abstrak, memecahkan masalah, berpikir logis dan memberikan alasan. Sedangkan Piaget percaya bahwa anak-anak membangun struktur mental mereka sendiri melalui serangkaian interaksi konstan dan aktif dengan lingkungan mereka (Galotti, 2004: 469).

Menurut Permendikbud No 137 Tahun 2014 tentang Standart Nasional Pendidikan Anak Usia Dini dijelaskan bahwa tingkat pencapaian perkembangan kognitif anak usia 5-6 tahun meliputi: (1) Menunjukkan aktivitas yang bersifat eksploratif dan menyelidik (seperti: apa yang terjadi ketika air ditumpahkan); (2) Memecahkan masalah sederhana dalam kehidupan sehari-hari dengan cara yang fleksibel dan diterima sosial; (3) Menerapkan pengetahuan atau pengalaman dalam konteks yang baru ; (4) Menunjukkan sikap kreatif dalam menyelesaikan masalah (ide, gagasan di luar kebiasaan); (5) Mengenal perbedaan berdasarkan ukuran: "lebih dari"; "kurang dari"; dan "paling/ter"; (6) Menunjukkan inisiatif dalam memilih tema permainan (seperti: "ayo kita bermain pura-pura seperti burung"); (7) Menyusun perencanaan kegiatan yang akan dilakukan; (8) Mengenal sebab-akibat tentang lingkungannya (angin bertiup menyebabkan daun bergerak, air dapat menyebabkan sesuatu menjadi basah); (9) Mengklasifikasikan benda berdasarkan warna, bentuk, dan ukuran (3 variasi) ; (10) Mengklasifikasikan benda yang lebih banyak ke dalam kelompok yang sama atau kelompok yang sejenis, atau kelompok berpasangan yang lebih dari 2 variasi; (11) Mengenal pola ABCDABCD; (12) Mengurutkan benda berdasarkan ukuran dari paling kecil ke paling besar atau sebaliknya; (13) Menyebutkan lambang bilangan 1-10 ; (14) Menggunakan lambang bilangan untuk menghitung; (15) Mencocokkan bilangan dengan lambang bilangan; (16) Mengenal berbagai macam lambang huruf vokal dan konsonan; (17) Merepresentasikan berbagai macam benda dalam bentuk gambar atau tulisan (ada benda pensil yang diikuti tulisan dan gambar pensil) 
Untuk melihat kemampuan kognitif anak salah satunya melalui kegiatan mengklasifikasikan benda. Menurut Carol Sefeld \& Barbara (2008: 394) klasifikasi adalah kegiatan mengelompokkan benda-benda yang serupa atau memiliki kesamaan. Sedangkan menurut Kamus Besar Bahasa Indonesia kata mengkasifikasi berarti menggolong-golongkan menurut jenis, menyusun dalam golongan. Suyanto (2005: 162) mengemukakan klasifikasi adalah mengelompokkan benda-benda kedalam beberapa kelompok. Karakteristik klasifikasi pada anak usia 5-6 tahun adalah anak mampu engklasifikasikan benda maupun objek berdasarkan cri kesamaan tertentu, yaitu dalam tiga kategori yakni berdasarkan warna, bentuk, dan ukuran. Anak usia dini belajarnya melalui benda-benda yang riil kemudian barulah ke berpikir yang abstrak, maka dari itu dalam pembelajaran mengklasifikasikan ini guru menggunakan media yang nyata.

\section{METODE PENELITIAN}

Penelitian ini merupakan jenis penelitian deskriptif dengan pendekatan kuantitatif. Subjek penelitian dalam penelitian ini adalah anak usia 5-6 tahun di kota dan kabupaten Sukabumi yang terdiri dari 6 TK, yaitu TK IT Al - Alawi, TK Islam Al - Fauza, TK Yasin, TK Islam Marjanul Qolbi, RA Darul Falaah, dan PAUD Al - Baaqi dengan jumlah keseluruhan adalah sebanyak 42 anak.

Berikut merupakan tabel data jumlah anak usia 5-6 tahun, nama TK dan jumlah anak yang akan menjadi subjek penelitian.

Tabel 1. Rincian Data Jumlah Anak TK Usia

5-6 Tahun di Kota dan Kabupaten Sukabumi

\begin{tabular}{|c|l|c|}
\hline NO & \multicolumn{1}{|c|}{ Nama Sekolah } & $\begin{array}{c}\text { Jumlah } \\
\text { Subjek }\end{array}$ \\
\hline 1 & TK IT Al - Alawi & 5 \\
\hline 2 & TK Islam Al - Fauza & 5 \\
\hline 3 & TK Yasin & 5 \\
\hline 4 & TK Islam Marjanul Qolbi & 5 \\
\hline 5 & RA Darul Falaah & 5 \\
\hline 6 & PAUD Al - Baaqi & 5 \\
\hline & Jumlah & 30 \\
\hline
\end{tabular}

Pengumpulan data dalam penelitian ini menggunakan teknik pengumpulan data pengamatan (observasi). Observasi dilakukan ketika anak berada di sekolah. Penelitian dilakukan mulai tanggal 4 April 2018 hingga 12 April 2018. Wawancara dilakukan pada guru kelas yang terlibat dalam kegiatan anak saat berada di sekolah. Wawancara yang digunakan adalah wawancara tidak terstruktur sehingga tidak menggunakan pedoman wawancara dengan tujuan untuk mengetahui faktor-faktor penyebab kurangnya kemampuan kogntif anak dalam mengklasifikasikan benda di TK Gugus I Kota dan Kabupaten Sukabumi. 
Data yang diperoleh dari sebuah penelitian kuantitatif harus memiliki validitas dan reabilitas. Validitas yang digunakan dalam penelitian ini adalah validitas isi. Validitas isi disusun berdasarkan dari pertimbangan- pertimbangan rasional dan konseptual para ahli dalam bidang terkait. Validitas instrumen pada penelitian ini menggunakan pendapat dari ahli (expert judgement) yaitu Bapak Indra Zultiar, M. Pd. Pengujian validitas dengan menggunakan expert judgement dilaksanakan dengan penelaahan terhadap kisi-kisi instrumen apakah telah sesuai dengan tujuan penelitian.

\section{HASIL DAN PEMBAHASAN}

Hasil temuan dilapangan menunjukkan bahwa perkembangan kognitif anak TK dikota dan kabupaten Sukabumi cenderung kurang. Hal ini dapat dilihat dari kemampunnya dalam menglasifikasikan benda seseuai warna, mengklasifikasikan benda sesuai bentuk, dan mengklasifkasikan benda sesuai ukuran. Data kemampuan menglasifikasikan ini dikategorikan menjadi empat kategori yaitu tidak mampu, kurang mampu, mulai mampu, dan mampu.

\section{a. Kemampuan anak dalam mengklasifikasikan benda sesuai warna}

Kemampuan rata-rata anak dalam mengklasifikasikan benda sesuai warna di TK IT Al - Alawi, TK Islam Al - Fauza, TK Yasin, TK Islam Marjanul Qolbi, RA Darul Falaah, dan PAUD Al - Baaqi disajikan melalui diagram dibawah ini:

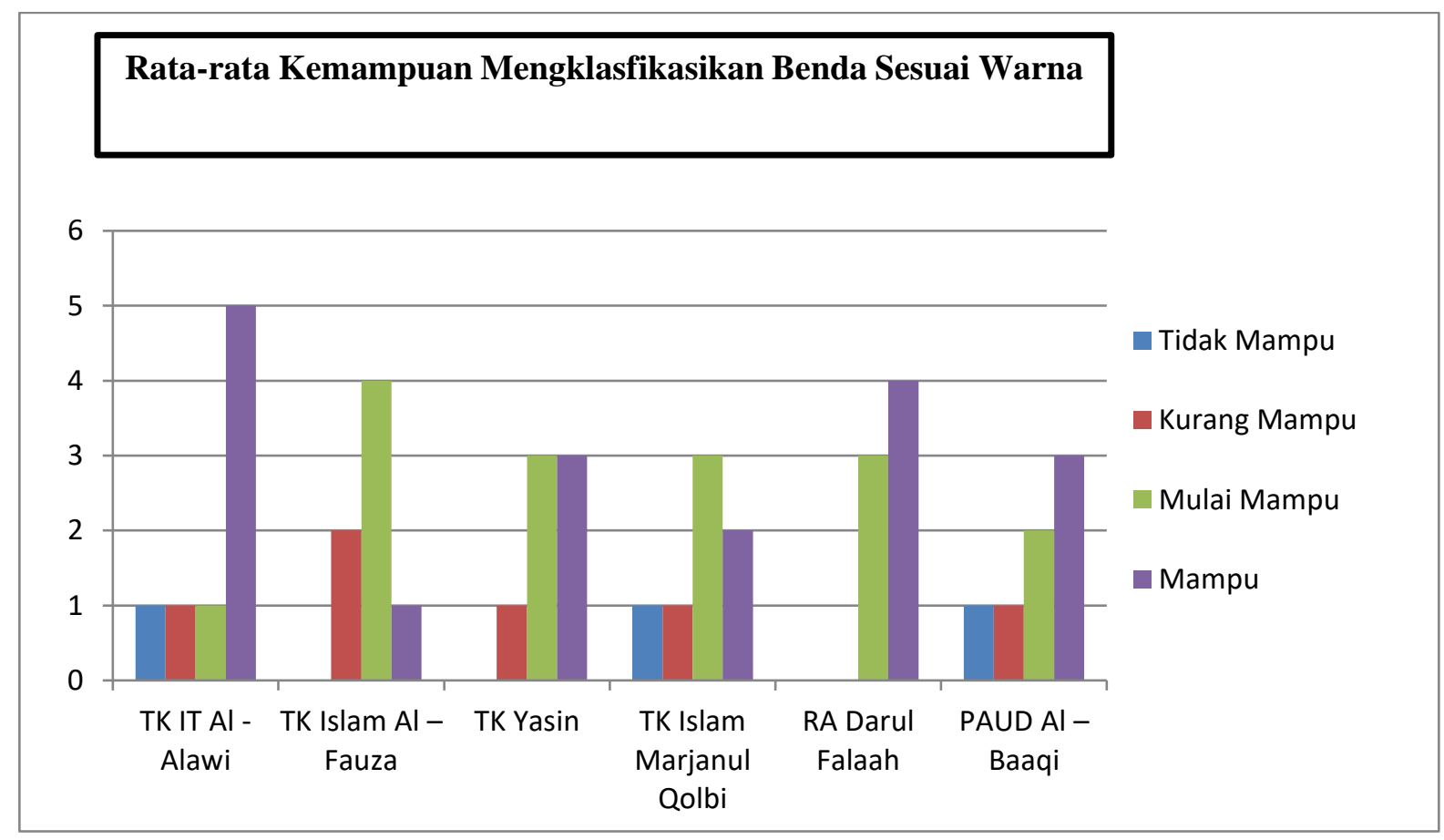

Gambar 1. Diagram batang mengklasifikasikan benda sesuai warna

Dari diagram diatas dapat dilihat bahwa kemampuan kogntif anak dalam mengklasifikasikan benda sesuai warna di TK IT Al-Alawi menunjukkan bahwa sebanyak 1 anak termasuk dalam kategori tidak mampu, 1 termasuk dalam kategori kurang mampu, 1 masuk kategori mulai mampu, dan 5 masuk kategori mampu. Kemudian di TK Islam Al-Fauza yaitu sebanyak 2 anak termasuk dalam kategori kurang mampu, 4 anak masuk kategori mulai 
mampu, dan 1 anak masuk kategori mampu. Di TK Yasin yaitu sebanyak 1 anak termasuk dalam kategori kurang mampu, 3 anak masuk kategori mulai mampu, dan 3 anak masuk kategori mampu. Adapun di TK Islam Marjanul Qolbi yaitu sebanyak 1 anak termasuk dalam kategori tidak mampu, 1 anak termasuk dalam kategori kurang mampu, 3 anak masuk kategori mulai mampu, dan 2 anak masuk kategori mampu. Kemudian di TK RA Darul Falaah yaitu sebanyak 3 anak masuk kategori mulai mampu, dan 4 anak masuk kategori mampu.Seangkan di PAUD Al Baaqi yaitu sebanyak 1 anak termasuk dalam kategori tidak mampu, 1 anak termasuk dalam kategori kurang mampu, 2 anak masuk kategori mulai mampu, dan 3 anak masuk kategori mampu.

\section{b. Kemampuan anak dalam mengklasifikasikan benda sesuai bentuk}

Dari diagram dibawah dapat dilihat bahwa kemampuan kogntif anak dalam mengklasifikasikan benda sesuai bentuk di TK IT Al - Alawi, TK Islam Al - Fauza, TK Yasin, TK Islam Marjanul Qolbi, RA Darul Falaah, dan PAUD Al - Baaqi disajikan melalui diagram dibawah ini:

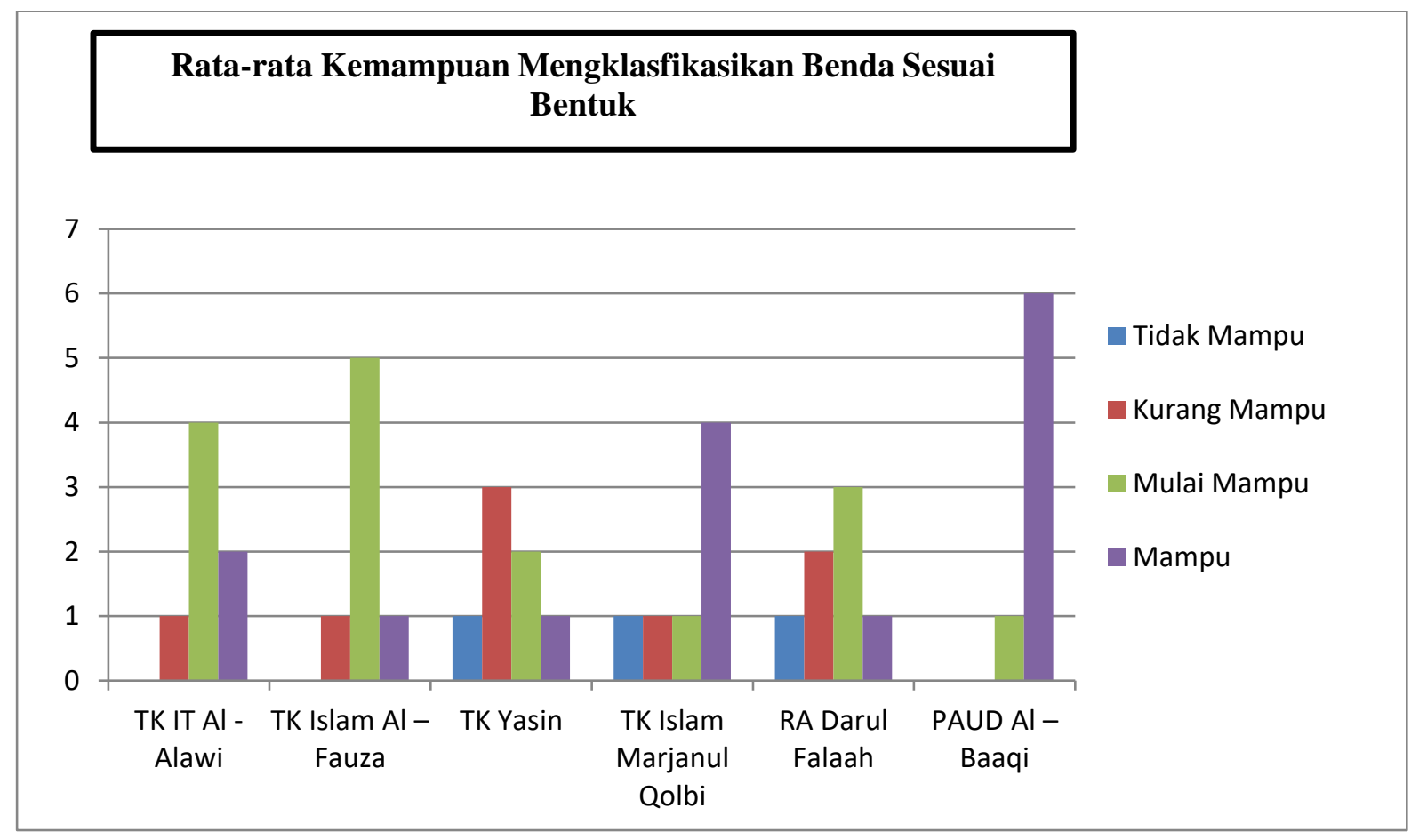

Gambar 2. Diagram batang mengklasifikasikan benda sesuai bentuk

Dari diagram diatas dapat dilihat bahwa kemampuan kogntif anak dalam mengklasifikasikan benda sesuai bentuk di TK IT Al-Alawi menunjukkan bahwa sebanyak 1 anak termasuk dalam kategori kurang mampu, 4 anak masuk dalam kategori mulai mampu, dan 2 masuk dalam kategori mampu. Kemudian di TK Islam Al-Fauza yaitu sebanyak 1 anak termasuk dalam kategori kurang mampu, 5 anak masuk kategori mulai mampu, dan 1 anak masuk kategori mampu. Di TK Yasin yaitu sebanyak 1 anak masuk dalam kategori tidak mampu, 3 anak termasuk dalam kategori kurang mampu, 2 anak masuk kategori mulai mampu, 
dan 1 anak masuk kategori mampu. TK Islam Marjanul Qolbi yaitu sebanyak 1 anak termasuk dalam kategori tidak mampu, 1 anak termasuk dalam kategori kurang mampu, 1 anak masuk kategori mulai mampu, dan 4 anak masuk kategori mampu. Lalu TK RA Darul Falaah yaitu sebanyak 1 anak termasuk dalam kategori tidak mampu, 2 anak termasuk dalam kategori kurang mampu, 3 anak masuk kategori mulai mampu, dan 1 anak masuk kategori mampu. Kemudian di PAUD Al Baaqi yaitu sebanyak 1 anak masuk kategori mulai mampu, dan 6 anak masuk kategori mampu.

\section{c. Kemampuan anak dalam mengklasifikasikan benda sesuai ukuran}

Dari diagram dibawah dapat dilihat bahwa kemampuan kogntif anak dalam mengklasifikasikan benda sesuai ukuran di TK IT Al - Alawi, TK Islam Al - Fauza, TK Yasin, TK Islam Marjanul Qolbi, RA Darul Falaah, dan PAUD Al - Baaqi disajikan melalui diagram dibawah ini:

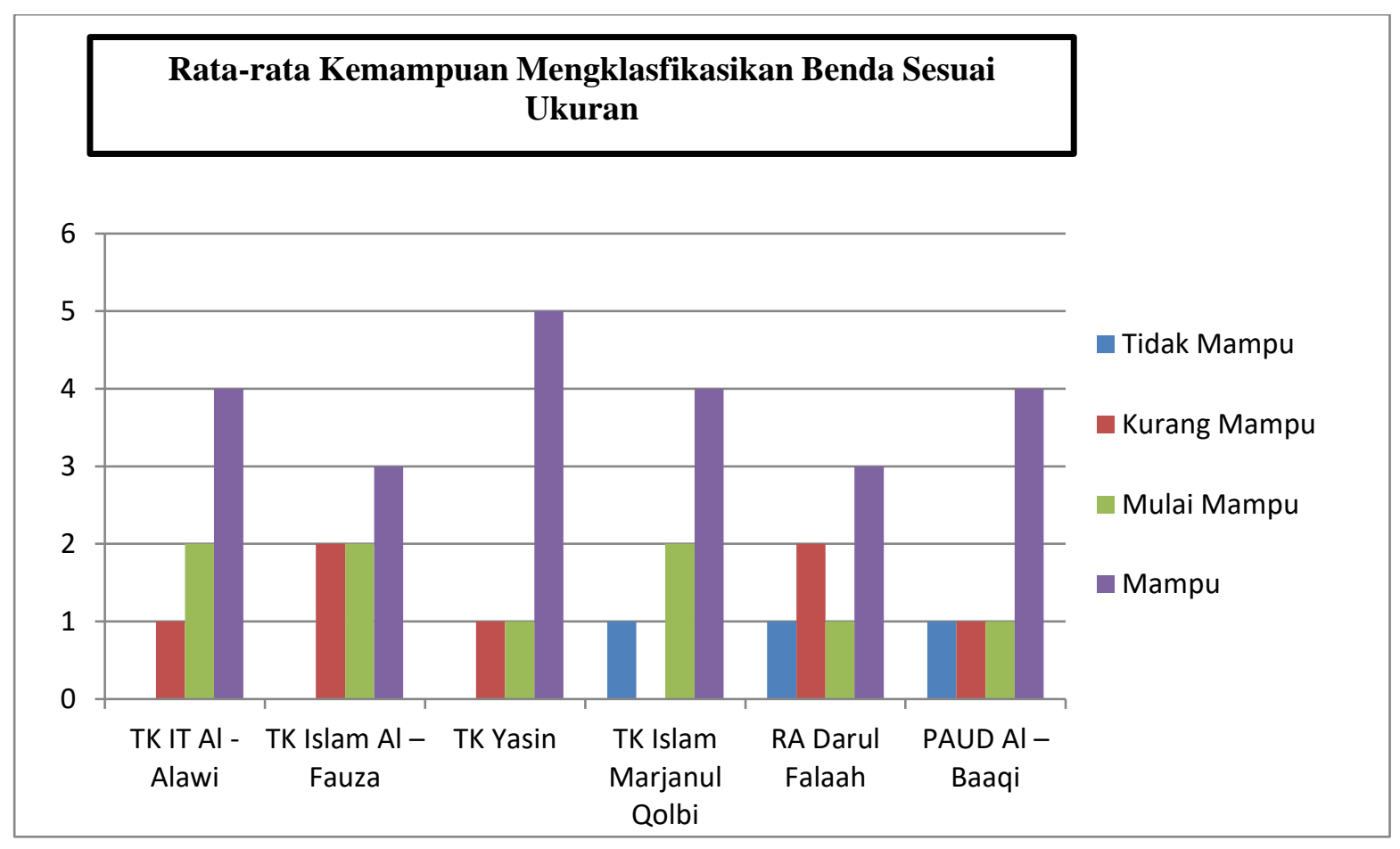

Gambar 3. Diagram batang mengklasifikasikan benda sesuai ukuran

Dari diagram diatas dapat dilihat bahwa kemampuan kogntif anak dalam mengklasifikasikan benda sesuai ukuran yang dilakukan di TK IT Al-Alawi menunjukkan bahwa sebanyak 1 anak termasuk dalam kategori kurang mampu, 2 anak masuk dalam kategori mulai mampu, dan 4 masuk dalam kategori mampu. Kemudian di TK Islam Al-Fauza yaitu sebanyak 2 anak termasuk dalam kategori kurang mampu, 2 anak masuk kategori mulai mampu, dan 3 anak masuk kategori mampu. Hasil penelitian yang dilakukan di TK Yasin yaitu sebanyak 1 anak termasuk dalam kategori kurang mampu, 1 anak masuk kategori mulai mampu, dan 5 anak masuk kategori mampu. Di TK Islam Marjanul Qolbi yaitu sebanyak 1 anak termasuk dalam kategori tidak mampu, 2 anak masuk kategori mulai mampu, dan 4 anak masuk kategori mampu. Di TK RA Darul Falaah yaitu sebanyak 1 anak termasuk dalam 
kategori tidak mampu, 2 anak termasuk dalam kategori kurang mampu, 1 anak masuk kategori mulai mampu, dan 3 anak masuk kategori mampu. Lalu PAUD Al Baaqi yaitu sebanyak 1 anak termasuk dalam kategori tidak mampu, 1 anak termasuk dalam kategori kurang mampu, 1 anak masuk kategori mulai mampu, dan 4 anak masuk kategori mampu.

Dari data kemampuan kogntif anak di kota dan kabupaten Sukabumi dalam mengklasifikasikan benda sesuai warna, mengklasifikasikan benda sesuai bentuk, mengklasifikasikan benda sesuai ukuran dapat di deskripsikan sebagai berikut.

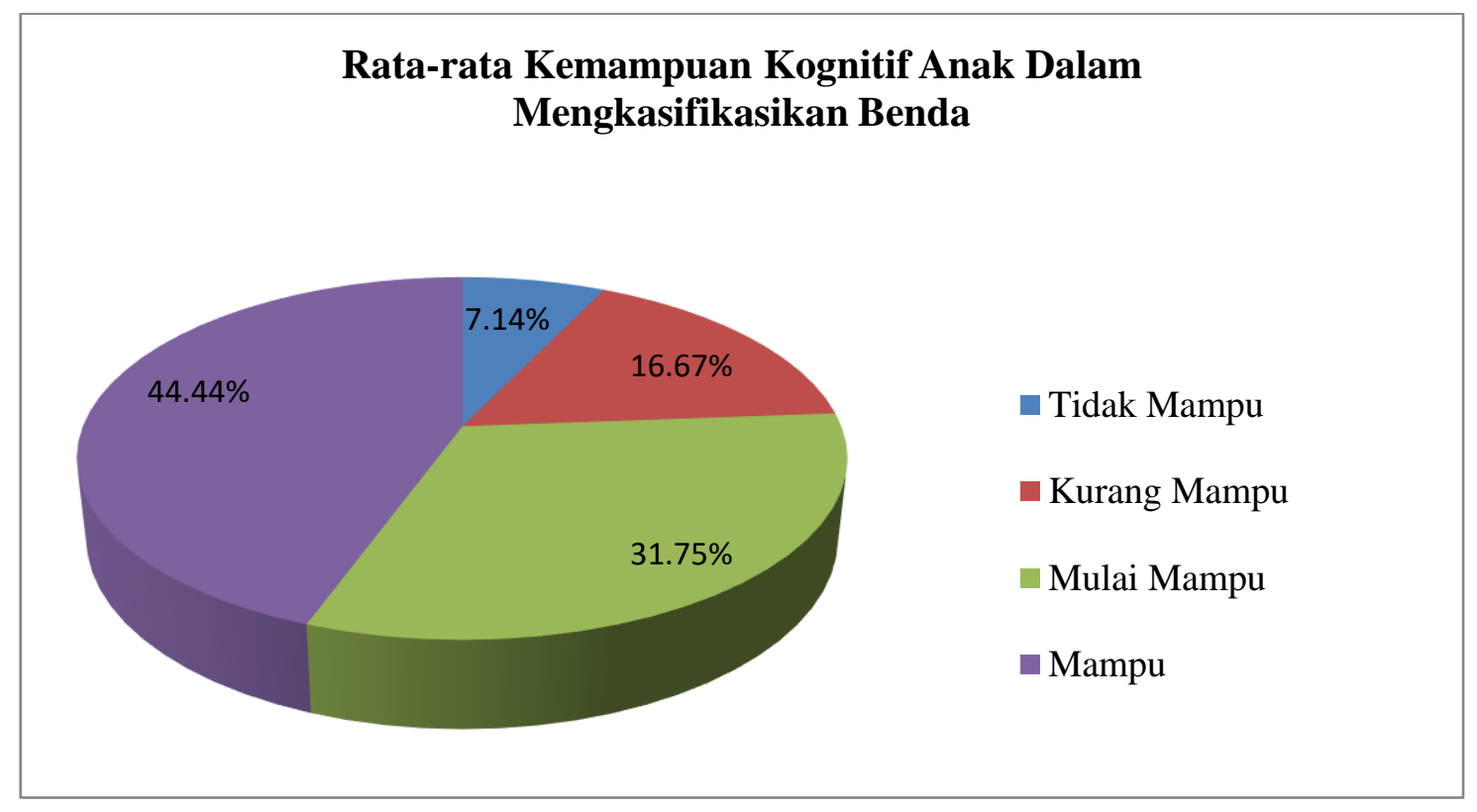

Gambar 4. Rata-rata kemampuan anak dalam mengkasifikasikan benda

Dari diagram diatas dapat dilihat bahwa kemampuan kogntif anak dalam mengklasifikasikan benda di Kabupaten dan Kota Sukabumi adalah 7,14 \% anak tidak mampu mengklasifikasikan benda, 16,67\% anak kurang mampu dalam mengklasifikasikan benda, 31,75 anak mulai mampu mengklasifikasikan benda, dan 44,44 \% anak mampu mengklasifikasikan benda. Hal ini menunjukkan bahwa perkembangan kognitif di TK se Kabupaten dan Kota Sukabumi sudah bagus, namun masih ada 23,81\% anak masih berada dalam kategori kurang dan tidak mampu.

\section{KESIMPULAN DAN SARAN}

Penelitian ini menunjukkan bahwa tingkat perkembangan anak di kota dan kabupaten Sukabumi sudah berkembang dengan baik. Hal ini dapat dilihat dalam kemampuan anak pada saat mengklasifikasikan benda.

Diharapkan kepada peneliti selanjutnya agar dapat mengembangkan hasil dari penelitian ini dan menambah variabel baru. Diharapkan kepada guru supaya menambah stimulus serta media untuk meningkatkan perkembangan kognitif anak agar berkembang secara optimal. Diharapkan kepada orang tua juga harus mengajarkan anak tentang berbagai hal untuk menngkatkan semua aspek perkembangan yang ada dalam diri anak, mengingat anak usia dini sedang berada dalam masa emas (golden age). 
Jurnal Golden Age Hamzanwadi University

Vol. 3 No. 1, Juni 2018, Hal. 35-43

E-ISSN : 2549-7367

\section{DAFTAR PUSTAKA}

Galotti, K. M. (2004). Cognitive Psychology: In And Out Of The Laboratory 'Third Edition'. USA: Thomson Learning.

Johnston, J. \& Halocha, J. (2010). Early Childhood And Primary Education. Ney York: Open University Press.

Permendikbud Nomer 137 Tahun 2014 Tentang Standar Pendidikan Anak Usia Dini.

Seefeldt, Carol \& Barbara A Wasik. (2008). Pendidikan Anak Usia Dini. Jakarta: PT Indeks.

Sujiono, Y. N. (2012). Konsep Dasar Pendidikan Anak Usia Dini. Jakarta: PT Indeks.

Suyanto, S Dkk. (2005). Dasar-Dasar Pendidikan Anak Usia Dini. Yogyakarta: Hikayat.

Undang-undang Nomer 20 Tahun 2003 tentang Sistem Pendidikan Nasional Bab I Pasal I butir 14 